\title{
Molecular Analysis of Genetic Diversity and Geographic Origin within an Ex Situ Germplasm Collection of Cherimoya by Using SSRs
}

\author{
P. Escribano, M.A. Viruel, and J.I. Hormaza ${ }^{1}$ \\ Estación Experimental La Mayora Consejo Superior de Investigaciones Científicas (CSIC), 29750 \\ Algarrobo-Costa, Málaga, Spain
}

\begin{abstract}
AdDITIONAL InDEX wORDs. Annona cherimola, genetic resources, genetic variability, microsatellites, molecular markers
Abstract. Cherimoya (Annona cherimola Mill.) is an underused fruit crop with a clear niche for expansion in subtropical climates. In this study, 16 simple sequence repeat (SSR) loci were used to find molecular polymorphisms among 279 cherimoya accessions from a worldwide ex situ field germplasm collection. A total of 79 amplification fragments were amplified with 16 pairs of SSR primers, with an average of 4.9 bands/SSR. Mean expected and observed heterozygosities averaged 0.53 and 0.44 , respectively. The total value for the probability of identity was 4.34 $\times 10^{-8}$. The SSRs studied resulted in 267 different fingerprinting profiles, of which 258 were unique genotypes; the rest were putative cases of synonymies or mislabeling errors. Unweighted pair group method with arithmetic averages (UPGMA) cluster analysis indicated the relationships among the analyzed accessions, showing some specific groups related to their geographical origins. Analysis of molecular variance (AMOVA) was performed to examine the distribution of genetic variation of the 148 accessions collected from putative cherimoya origin areas in Ecuador and Peru, showing that the major variations occurred within valleys in each country. The results confirmed the usefulness of microsatellites for identification of genetic diversity and geographic origin of cherimoya and are discussed in terms of their implications for ex situ conservation of cherimoya genetic resources.
\end{abstract}

The cherimoya belongs to the Annonaceae, or soursop, family, which is included within the order Magnoliales in the basal Angiosperm clade Magnoliid. Annonaceae is one of the largest tropical and subtropical families of trees, shrubs, and lianas. It has about 135 genera and 2500 species distributed worldwide, 900 of which are found in the Neotropics (Chatrou et al., 2004). Three genera in the Annonaceae (Annona L., Rollinia St.-Hil., and Asimina Adans.) contain species with edible fruit, such as cherimoya ( $A$. cherimola), sugar apple (Annona squamosa L.), atemoya (a hybrid between $A$. cherimola and A. squamosa), soursop (Annona muricata L.), custard apple (Annona reticulata L.), ilama (Annona diversifolia Saff.), soncoya (Annona purpurea Moc. et Sessé), biriba (Rollinia mucosa Baill.), and pawpaw [Asimina triloba (L.) Dunal.], all of them nondomesticated or in an incipient stage of domestication. Cherimoya, atemoya, and soursop are the most important worldwide, both commercially and for local consumption.

Most authors (Bonavia et al., 2004; Popenoe, 1921, 1974; Van Damme et al., 2000) consider the inter-Andean valleys of Ecuador and Peru, where wild populations and cultivated trees grow between 1200 and $2000 \mathrm{~m}$, as the area of origin of cherimoya. However, $A$. cherimola is the only representative of a group of closely related species that occur exclusively in Mesoamerica, and this has led other researchers (Pozorski and Pozorski, 1997) to propose Mesoamerica as the center of origin

Received for publication 20 Oct. 2006. Accepted for publication 28 Jan. 2007. Financial support for this work was provided by the Spanish Ministry of Education (Project Grant AGL2004-02290/AGR) and the European Union under the INCO-DEV program (Contract 015100). P.E. was supported by an FPI grant of the Spanish Ministry of Education.

We gratefully acknowledge J.M. Farré and J.M. Hermoso for valuable information on cherimoya germplasm and X. Scheldeman for critical comments on the manuscript.

${ }^{1}$ Corresponding author. E-mail: ihormaza@eelm.csic.es. of this species. In any case, cherimoya fruit were consumed in the Andean region in antiquity (Popenoe et al., 1989), and movement of germplasm along Mesoamerica, southern Mexico, and northern South America took place in pre-Columbian times (Van Damme et al., 2000). Early Spanish explorers introduced cherimoya in Spain, and from Spain it extended to other southern European countries. Currently, cherimoya is an underused fruit crop with a clear niche for expansion in developing countries with subtropical climates. World production is low; in fact, Spain, with just 3000 ha, is the main world producer, followed by Chile. It is also produced on a limited commercial scale in other Latin American countries, such as Peru, Ecuador, and Bolivia, where most of the cherimoyas are collected from wild trees or from small family orchards with very limited market involvement. A large proportion of the trees is found in a semicultivated state, originating as either chance seedlings or planted by humans who grow cherimoyas at the borders of paths or orchards, with application of very limited cultural practices.

Cherimoya presents protogynous dichogamy, with hermaphroditic flowers wherein the female and male structures do not mature simultaneously, generally preventing self-fertilization in the same flower (Schroeder, 1971). At anthesis, the flowers are in female stage with receptive stigmas. The following day, the flower switches to the male stage, where the anthers start to dehisce and the stigmas are no longer receptive. Due to the lack both of overlap between male and female stages in cherimoya and of proper pollinating agents outside its native range, hand pollination with pollen and stamens together is a common practice for commercial production (Schroeder, 1971). The most important producing countries have developed clonal selections well adapted to their climatic conditions: 'Fino de Jete' and 'Campas' in Spain, 'White' and 'Bays' in California, 'Concha Lisa' and 'Bronceada' in Chile, and 'Cumbe' in Peru. The most important breeding 
objectives include reduction or elimination of seeds in the fruit as well as development of advanced cultivars with better postharvest shelf life and resistance/tolerance to fruit flies of the genera Ceratitis MacLeay and Anastrepha Schiner.

Increasing concerns on reduced levels of genetic diversity in crop species (Esquinas-Alcazar, 2005; Tanksley and McCouch, 1997) have led to the need to preserve as much genetic diversity as possible both in situ and ex situ, not only for the long-term survival of the species controlling genetic erosion but also to maintain enough variability for breeding programs. However, in most fruit tree species, such as cherimoya, lack of information on the distribution of genetic variability in natural populations and existing germplasm collections hinders efficient management of genetic resources. Thus, to preserve cherimoya genetic resources for future generations, a cherimoya germplasm collection was established at the beginning of the 1980s at the E.E. La Mayora Consejo Superior de Investigaciones Científicas (CSIC) in Malaga, Spain. This is the most important cherimoya germplasm collection worldwide, and it currently maintains 279 accessions, most of them collected in the Andean region of Peru and Ecuador, along with local Spanish cultivars and accessions introduced by collaboration and exchange with other cherimoya-producing countries.

Maintaining and evaluating plant genetic resources is expensive, especially in vegetatively propagated species such as most fruit trees, where accessions are stored in ex situ field germplasm banks. Optimization of genetic resource management requires precise identification of the accessions as well as correct evaluation of the amount and distribution of genetic diversity within a species. In cherimoya, as in other fruit species, morphological descriptors have traditionally been used to characterize and distinguish the different accessions (AndrésAgustín et al., 2006; Pérez de Oteyza et al., 1999). However, cultivar identification based exclusively on phenotypic traits is labor intensive and can be inaccurate due to the influence of the environment, subjectivity in the evaluation of traits, and the limiting number of discriminating traits. Therefore, molecular markers are being increasingly used to optimize plant genetic resource management. However, several molecular studies have been carried out in cherimoya, including studies of isozymes (Ellstrand and Lee, 1987; Pascual et al., 1993; Perfectti and Pascual, 1998), random amplified polymorphic DNAs (RAPDs) (Ronning et al., 1995), and amplified fragment length polymorphisms (AFLPs) (Rahman et al., 1998). Microsatellites or SSRs have become the markers of choice for fingerprinting purposes in most plant species (Gupta and Varshney, 2000), due to their high polymorphism, codominance, and reproducibility. Recently, a set of SSRs was reported for the first time in cherimoya that has been shown to be highly transferable to other species in the Annonaceae (Escribano et al., 2004).

In this work, we used 16 microsatellites to analyze 279 cherimoya accessions conserved in the Spanish cherimoya germplasm bank, aiming to identify the accessions conserved, to determine the possible homonymies and synonymies, and to study the genetic diversity conserved in the collection as well as the population structure of the accessions collected directly in the field in the putative cherimoya area of origin in Peru and Ecuador.

\section{Materials and Methods}

Plant material and genomic DNA extraction. Two hundred seventy-nine cherimoya accessions from diverse geographical areas maintained at the CSIC were analyzed in this study. The accessions studied can be divided into two main groups according to their origin: accessions collected directly from the field in the putative cherimoya area of origin in Peru (123) and Ecuador (37) (Table 1) and 119 additional accessions (Table 2) including some with unknown origin from Peru and Ecuador together with those from other American countries (Bolivia, Chile, Colombia, Costa Rica, or Mexico), where movement of cherimoya germplasm has taken place since pre-Columbian times, Mediterranean countries (Spain, Portugal, and Italy) where cherimoya was introduced in post-Columbian times, and other countries such as the United States or Australia with most recent introduction.

DNA was extracted from young leaves from two plants of each of the 279 accessions following the protocol of Viruel and Hormaza (2004).

SSR ANALYSIS. Sixteen cherimoya SSRs [13 from Escribano et al. (2004) and 3 from P. Escribano, M.A. Viruel, and J.I. Hormaza, unpublished] were selected for SSR fingerprinting (Table 3). A reaction solution $(15 \mu \mathrm{L})$ containing $16 \mathrm{~mm}$ $\left(\mathrm{NH}_{4}\right)_{2} \mathrm{SO}_{4}, 67 \mathrm{~mm}$ Tris- $\mathrm{HCl}, \mathrm{pH} 8.8,0.01 \%$ polyoxyethylene sorbitan monolaurate (Tween 20), $2 \mathrm{~mm} \mathrm{MgCl}_{2}, 0.1 \mathrm{~mm}$ each $\mathrm{dNTP}, 0.4 \mu \mathrm{M}$ each primer, $25 \mathrm{ng}$ genomic DNA, and 0.5 unit of BioTaq DNA polymerase (Bioline, London) were used for amplification on an I-cycler thermocycler (Bio-Rad Laboratories, Hercules, Calif.) using the following temperature profile: initial step of $1 \mathrm{~min}$ at $94{ }^{\circ} \mathrm{C}, 35$ cycles of $30 \mathrm{~s}$ at $94{ }^{\circ} \mathrm{C}, 30 \mathrm{~s}$ at $45-55^{\circ} \mathrm{C}$ (Table 3 ), and $1 \mathrm{~min}$ at $72{ }^{\circ} \mathrm{C}$, with a final step of $5 \mathrm{~min}$ at $72^{\circ} \mathrm{C}$. Forward primers were labeled with a fluorescent dye on the $5^{\prime}$ end. The PCR products were analyzed by capillary electrophoresis in a CEQ 8000 capillary DNA analysis system (Beckman Coulter, Fullerton, Calif.). Samples were denaturalized at $90{ }^{\circ} \mathrm{C}$ during $120 \mathrm{~s}$, injected at $2.0 \mathrm{kV}$, $30 \mathrm{~s}$, and separated at $6.0 \mathrm{kV}$ during $35 \mathrm{~min}$. Each reaction was repeated twice, and the Spanish cultivar Fino de Jete was used as control in each run to ensure size accuracy and to minimize run-to-run variation.

DiVersity PARAMETERS. Allelic composition of each accession and numbers of total alleles were determined for each SSR locus. Putative alleles were indicated by the estimated size, in bp. Diversity analyses were assessed only for accessions with no homozygous null alleles and one or two bands per microsatellite individual phenotype using the following parameters: number of alleles per locus (A), observed heterozygosity [Ho (direct count)], expected heterozygosity [He $\left(1-\sum p_{i}{ }^{2}\right.$, where $p_{i}$ is the frequency of the $i$ th allele; Nei, 1973)], effective number of alleles [Ne (1/1 - He)], Wright's fixation index [F (1/ $1-\mathrm{Ho} / \mathrm{He}$ ) (Wright, 1951)], and the probability of identity \{PI $\left[1-\sum p_{i}{ }^{4}+\sum \sum\left(2 p_{i} p_{j}\right)^{2}\right.$, where $p_{i}$ and $p_{j}$ are the frequency of the $i$ th and $j$ th alleles, respectively] $\}$, which measures the probability that two randomly drawn diploid genotypes will be identical assuming observed allele frequencies and random assortment (Paetkau et al., 1995). Total probability of identity, defined as the probability of two cultivars sharing the same genetic profile by chance, was also calculated from the individual PI values.

Significant deviations $(P<0.01)$ from Hardy-Weinberg equilibrium (HWE) at individual loci were tested using a Markov chain method. The program ARLEQUIN, version 3.01 (Excoffier et al., 2005), was used to calculate A, Ho, He, allele frequencies (considering $P<0.05$ and $P>0.9$ as rare and 
Table 1. Origin according to passport data of the 160 tested cherimoya accessions collected directly from the putative cherimoya area of origin in Peru and Ecuador. ${ }^{\mathrm{z}}$

\begin{tabular}{|c|c|c|c|c|c|c|c|c|}
\hline$\overline{\text { Accession }}$ & Region/province & Place & Accession & Region/province & Place & Accession & Region/province & Place \\
\hline$\overline{\text { SE1 }}$ & Pichincha & Cumbaya & SP20 & Lima & Yunguy & SP83 & Cajamarca & San Pablo \\
\hline SE2 & Pichincha & Cumbaya & SP22 & Ancash & La Pampa & SP84 & Cajamarca & San Pablo \\
\hline SE3 & Pichincha & Guayllabamba & SP23 & Ancash & Patay & SP85 & Cajamarca & San Pablo \\
\hline SE4 & Pichincha & Guayllabamba & SP25 & Ancash & Masin & SP86 & Cajamarca & San Pablo \\
\hline SE5 & Pichincha & Guayllabamba & SP26 & Ancash & Masin & SP87 & Cajamarca & San Pablo \\
\hline SE6 & Pichincha & Guayllabamba & SP27 & Ancash & Masin & SP88 & Cajamarca & San Pablo \\
\hline SE8 & Pichincha & Guayllabamba & SP29 & Ancash & Yunguilla & SP89 & Cajamarca & San Pablo \\
\hline SE9 & Pichincha & Guayllabamba & SP33 & Cajamarca & Asuncion & SP90y & Cajamarca & San Pablo \\
\hline SE10 & Pichincha & Guayllabamba & SP34 & Cajamarca & Asuncion & SP91 & Cajamarca & San Pablo \\
\hline SE11 & Pichincha & Puellaro & SP35 & Cajamarca & Asuncion & SP92 & Cajamarca & San Pablo \\
\hline SE12 & Pichincha & Puellaro & SP36 & Cajamarca & Asuncion & SP93 & Cajamarca & San Pablo \\
\hline SE13 & Pichincha & Puellaro & SP38 & Cajamarca & Asuncion & SP94 & Cajamarca & San Pablo \\
\hline SE14 & Pichincha & Puellaro & SP39 & Cajamarca & Asuncion & SP95 & Cajamarca & San Pablo \\
\hline SE15 & Pichincha & Puellaro & SP40 & Cajamarca & Asuncion & SP96 & Cajamarca & San Pablo \\
\hline SE16 $6^{y}$ & Pichincha & Puellaro & SP41 & Cajamarca & Asuncion & SP102 & Piura & Huancabamba \\
\hline SE17 & Pichincha & Puellaro & SP42 & Cajamarca & Asuncion & SP104 & Piura & Huancabamba \\
\hline SE18 & Pichincha & Puellaro & SP43 & Cajamarca & Asuncion & SP106 & Piura & Huancabamba \\
\hline SE19 & Pichincha & Puellaro & SP44 & Cajamarca & Asuncion & SP107 & Piura & Huancabamba \\
\hline SE20 & Pichincha & Puellaro & SP45 & Cajamarca & Asuncion & SP110 & Huanuco & Cacha \\
\hline SE21 & Pichincha & Puellaro & SP46 & Cajamarca & Asuncion & SP111 & Huanuco & Cacha \\
\hline SE22 & Pichincha & Perucho & SP47 & Cajamarca & Asuncion & SP114 & Huanuco & Rio Llanayacu \\
\hline SE23y & Loja & Gonzamaná & SP48 & Cajamarca & Asuncion & SP115 & Huanuco & Rio Llanayacu \\
\hline SE24 $4^{y}$ & Loja & Gonzamaná & SP49 & Cajamarca & Asuncion & SP116 & Huanuco & Rio Llanayacu \\
\hline SE25 & Pichincha & Puellaro & SP50 & Cajamarca & Asuncion & SP117 & Huanuco & Rio Llanayacu \\
\hline SE26 & Pichincha & Puellaro & SP51 & Cajamarca & Asuncion & SP118 & Huanuco & Rio Llanayacu \\
\hline SE27 & Pichincha & Puellaro & SP52 & Cajamarca & Asuncion & SP119 & Huanuco & Rio Llanayacu \\
\hline SE28 & Pichincha & Puellaro & SP53 & Cajamarca & Asuncion & SP121 & Huanuco & Rio Llanayacu \\
\hline SE29 & Pichincha & Puellaro & SP54 & Cajamarca & Asuncion & SP122 & Huanuco & Rio Llanayacu \\
\hline SE30 & Pichincha & Puellaro & SP55 & Cajamarca & Asuncion & SP123 & Huanuco & Rio Llanayacu \\
\hline SE31 & Pichincha & Puellaro & SP56 & Cajamarca & Asuncion & SP125 & Huanuco & Rancho \\
\hline SE33 & Pichincha & Puellaro & SP57 & Cajamarca & Asuncion & SP126 & Huanuco & Rancho \\
\hline SE34 & Pichincha & Puellaro & SP58 & Cajamarca & Asuncion & SP127 & Huanuco & Rancho \\
\hline SE35 & Pichincha & Puellaro & SP59 & Cajamarca & Asuncion & SP128 & Lima & Callahuanca \\
\hline SE36 & Pichincha & Puellaro & SP60 & Cajamarca & Asuncion & SP129 & Lima & Callahuanca \\
\hline SE37 & Pichincha & Puellaro & SP61 & Cajamarca & Asuncion & SP130 & Lima & Callahuanca \\
\hline SE38 & Pichincha & Puellaro & SP62 & Cajamarca & Asuncion & SP131 & Lima & San Jeronimo \\
\hline SE39 & Pichincha & Puellaro & SP64 & Cajamarca & Asuncion & SP132 & Lima & San Jeronimo \\
\hline Cumbe $^{y}$ & Lima & Cumba & SP65 & Cajamarca & San Pablo & SP133 & Lima & Bellavista \\
\hline SP1 & Lima & Huanangui & SP66 & Cajamarca & San Pablo & SP134 & Lima & Yunguy \\
\hline SP2 & Lima & Huanangui & SP67 & Cajamarca & San Pablo & SP135 & Lima & Yunguy \\
\hline SP3 & Lima & Huanangui & SP68 & Cajamarca & San Pablo & SP136 & Lima & Yunguy \\
\hline SP4 ${ }^{y}$ & Lima & Huanangui & SP69 & Cajamarca & San Pablo & SP137 & Lima & Yunguy \\
\hline SP5 & Lima & Huanangui & SP71 & Cajamarca & San Pablo & SP138 & Lima & Yunguy \\
\hline SP6 & Lima & Huanangui & SP72 & Cajamarca & San Pablo & $\mathrm{SP} 201^{\mathrm{y}}$ & Cajamarca & Jesus \\
\hline SP7 & Lima & Huanangui & SP73 & Cajamarca & San Pablo & SP202 & Cajamarca & Jesus \\
\hline SP8 & Lima & Huanangui & SP74 & Cajamarca & San Pablo & SP203 ${ }^{y}$ & Cajamarca & Cajabamba \\
\hline SP10 & Lima & Huanangui & SP75 & Cajamarca & San Pablo & SP204 & Cajamarca & Cajabamba \\
\hline SP11 & Lima & Lancha & SP76 & Cajamarca & San Pablo & SP205 & Cajamarca & Cajabamba \\
\hline $\mathrm{SP} 12^{\mathrm{y}}$ & Lima & Lancha & SP77 & Cajamarca & San Pablo & SP206 & Cajamarca & Cajabamba \\
\hline SP13 & Lima & Lancha & SP78 & Cajamarca & San Pablo & SP207y & Cajamarca & Cajabamba \\
\hline SP15 & Lima & Yunguy & SP79 & Cajamarca & San Pablo & SP208 & Cajamarca & Cajabamba \\
\hline SP17 & Lima & Yunguy & SP80 & Cajamarca & San Pablo & SP210 & Cajamarca & Cajabamba \\
\hline SP18 & Lima & Yunguy & SP81 & Cajamarca & San Pablo & & & \\
\hline SP19 & Lima & Yunguy & SP82 & Cajamarca & San Pablo & & & \\
\hline
\end{tabular}

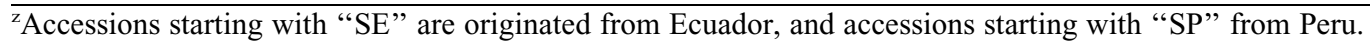

'Indicates accessions not included in the analysis of genetic structure. 
Table 2. Origin according to passport data of the 119 cherimoya accessions included in this study that were not collected directly from Peru and Ecuador.

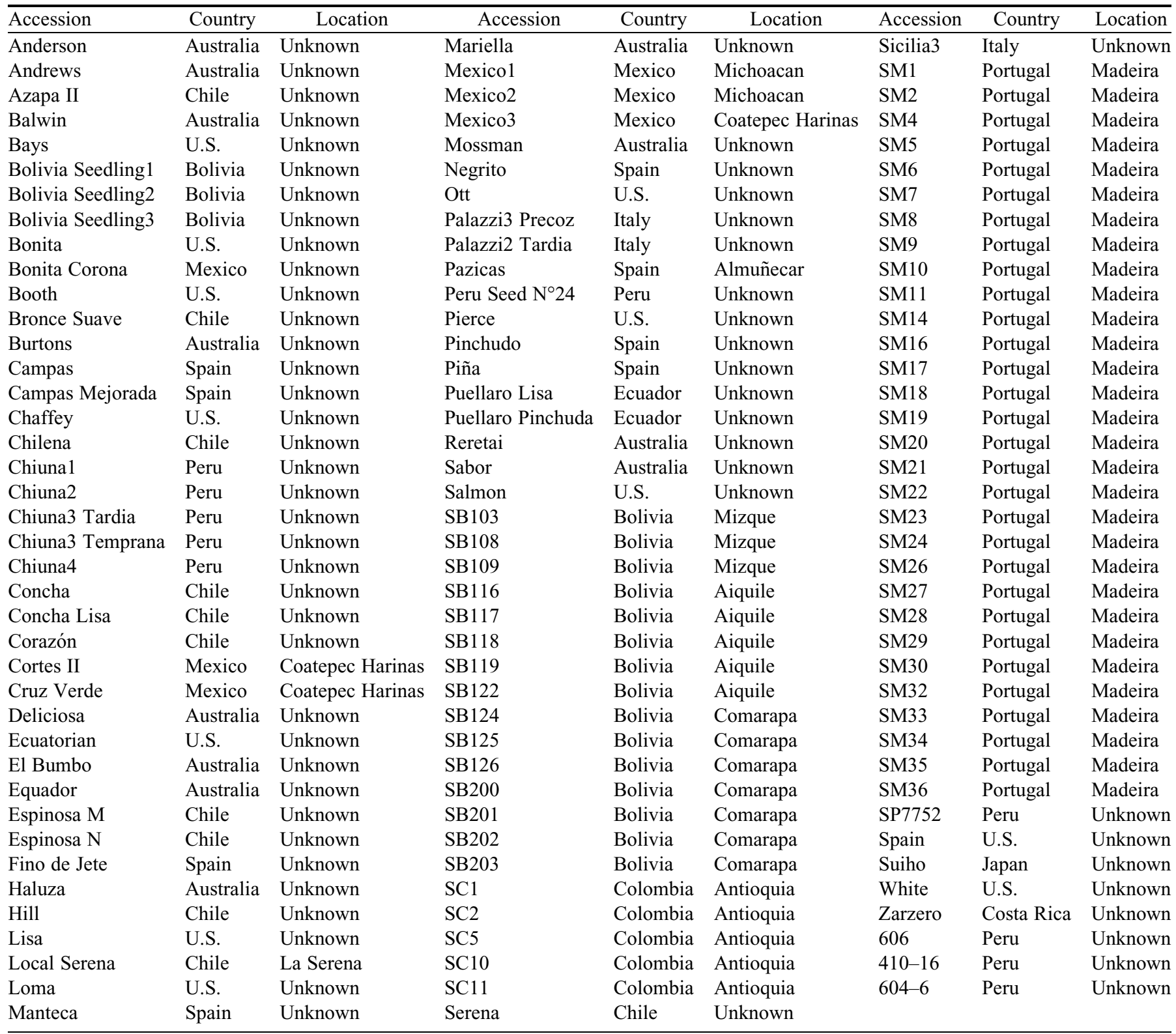

fixed alleles, respectively), and departure from HWE. POPGENE 1.32 software (Yeh and Boyle, 1997) was used to calculate $\mathrm{Ne}$ and $\mathrm{F}$. PI was calculated by IDENTITY 1.0 (Center for Applied Genetics, University of Agricultural Sciences, Vienna, Austria).

Genetic relationships among the accessions studied were calculated using UPGMA cluster analysis of the similarity matrix obtained from the proportion of shared amplification fragments (Nei and Li, 1979) with NTSYSpc 2.11 (Exeter Software, Stauket, N.Y.). The cophenetic correlation coefficient was computed for the dendrogram after the construction of a cophenetic matrix to measure the goodness of fit between the original similarity matrix and the dendrogram. Bootstrap support values were obtained from 2000 replicates using the program TREECON 1.3b (Van de Peer and De Wachter, 1994).

GEOGRAPHIC DISTRIBUTION OF GENETIC DIVERSITY. Distribution of genetic diversity was studied for the accessions collected directly from the field in Peru and Ecuador, excluding those accessions of unknown exact origin, with homozygous null alleles or with a microsatellite phenotype of more than two bands, through an analysis of molecular variance (AMOVA) using ARLEQUIN 3.01 (Excoffier et al., 2005) based on the number of different alleles and 10,000 permutations. Finally, 114 accessions from Peru and 34 from Ecuador were analyzed (Table 1). The analysis included five different regions in Peru-Piura (four accessions) and Cajamarca (64 accessions) in the north and Ancash (six accessions), Huanuco (14 accessions), and Lima (26 accessions) in the center-and one province (Pichincha with 34 accessions) in Ecuador (Fig. 1). An additional subdivision consisted in grouping the accessions by valleys within the regions/provinces. Different and combined hierarchical levels were established (i.e., among regions, among valleys, among valleys within regions, and within valleys). $F$ statistics relative to each component (i.e., $F_{C T}$ 
Table 3. Polymorphic SSRs used to analyze a germplasm collection of 279 cheimoya genotypes.

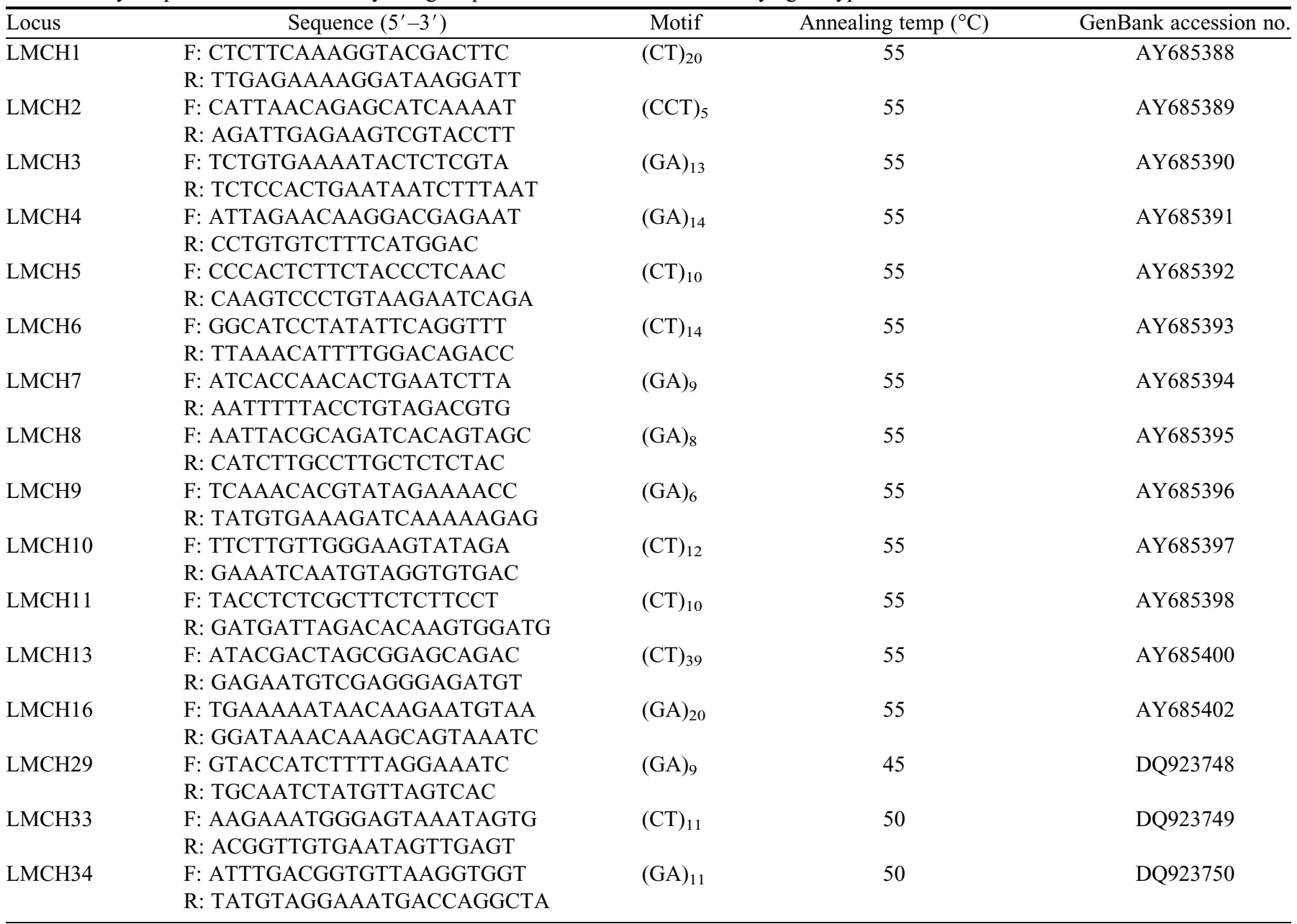

among regions/provinces, $F_{S C}$ among valleys within regions/ provinces, and $F_{S T}$ within valleys) were computed. Pairwise $F_{S T}$ values obtained from AMOVA calculations were used to measure the genetic differentiation between populations, and its significance $(P<0.01$ and $P<0.001)$ was assessed using a nonparametric permutation approach (Excoffier et al., 1992). Pairwise $F_{S T}$ values between regions/provinces were used to construct a UPGMA dendrogram using NTSYSpc 2.11.

\section{Results}

SSR POLYMORPHISM AND GENETIC DIVERSITY. The level of polymorphism of the 16 SSRs studied was initially investigated in all 279 accessions. The parameters of variability analyzed are presented in Table 4. A total of 79 amplification fragments were detected, with an average of 4.9 fragments/SSR. Five accessions showed three bands with some SSRs (SP207 with LMCH4; SP90 with LMCH6; Mexico1 with LMCH7; Mexico3 with LMCH10; and SM8 with LMCH16). Nonamplifying (null) alleles were observed in two loci: LMCH13 with five accessions (SB118, SB201, SP4, SP12, SP203) and LMCH7 with only one genotype (Bolivia Seedling 3). Genotypes with three and null alleles were excluded from the diversity analysis. For the remaining 268 accessions, a total of 78 alleles were detected. The number of alleles per locus ranged from 2 to 10 , with an average of 4.87 alleles per locus; the effective number of alleles ranged from 1.16 to 4.57 , with an average of 2.61. Allele frequencies ranged from 0.001 to 0.92 . Only one completely fixed allele $(P>0.9)$ was detected in LMCH34, and 25 alleles $(32 \%)$ were considered rare $(P<0.05)$. Five accessions ('Anderson', 'Andrews', 'Fino de Jete', 'Pierce', and SC10) showed the presence of one genotype-specific fragment, and one allele was only present in 10 accessions originated from Madeira (Portugal).

Expected heterozygosity $\left(H_{\mathrm{e}}\right)$ ranged from 0.14 in LMCH34 to 0.78 in LMCH29 (mean of 0.53 ). Observed heterozygosity $\left(H_{\mathrm{o}}\right)$ ranged from 0.10 in $\mathrm{LMCH} 34$ to 0.66 in $\mathrm{LMCH} 29$ (mean of 0.44). For all of the loci, the observed heterozygosity was lower than the expected one, and, consequently, all the $F$ values are positive with an average over all of the SSRs of 0.19 , showing heterozygote deficiency. Significant departure over HardyWeinberg expectations $(P<0.01)$ was observed for 14 loci. Regarding the probability of identity, the maximum $(0.75)$ was detected in LMCH34 with 4 alleles, and the minimum (0.15) in LMCH16 and LMCH29, both with 6 alleles. The average was 0.39 , and the total probability of identity was $4.34 \times 10^{-8}$.

Fingerprinting AND GENETIC RELATIONSHIPS AMONG ACCESSIONS. The combination of different amplified fragments 


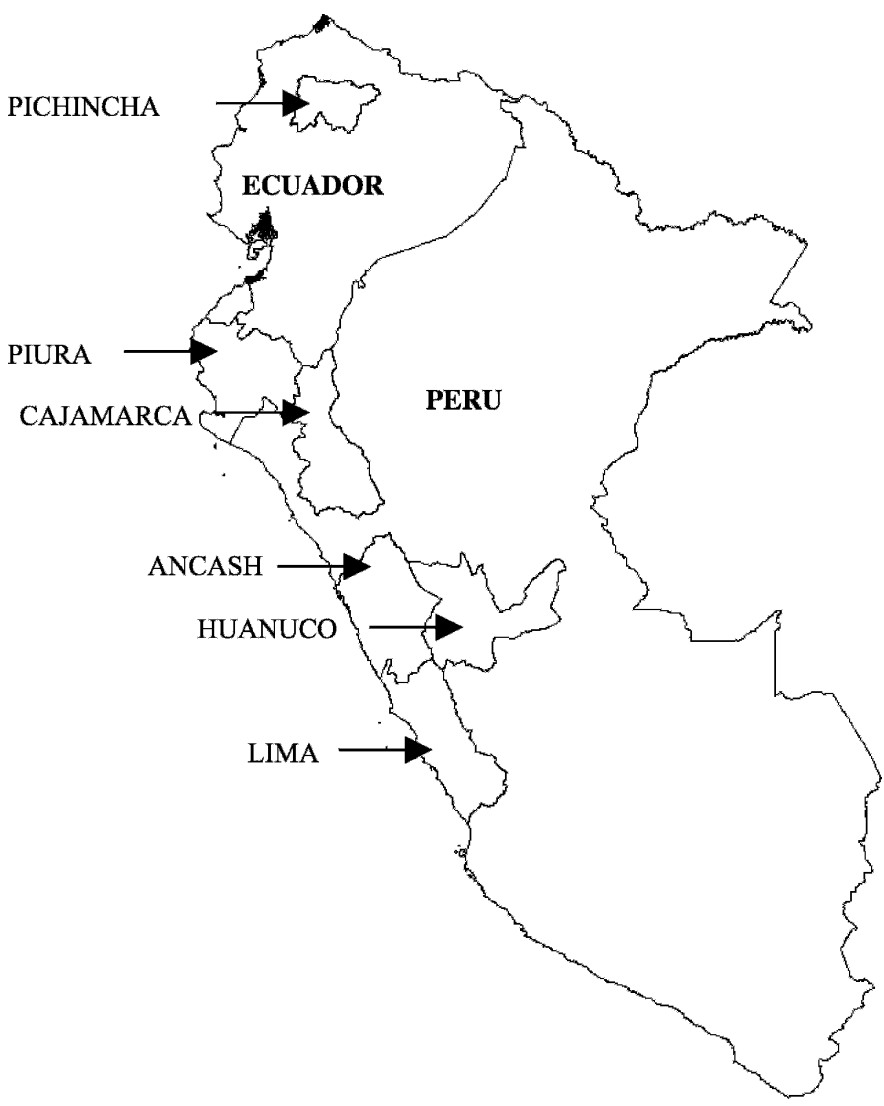

Fig. 1. Map showing the location of the regions in Peru and provinces in Ecuador where cherimoya accessions were collected directly from the field.

with 16 pairs of SSR primers allowed us to obtain 267 different profiles; of those, 258 corresponded to unique genotypes, and the remaining 9 were undistinguishable for two or three accessions. The six groups with two undistinguishable accessions include three from Peru (SP67-SP68; SP39-SP90; SP20-
SP201), one from Ecuador (SE6-SE16), and two from Portugal (SM26-SM29; SM6-SM22). The three groups with three undistinguishable accessions include one from Peru (Chiuna3Temprana-Cumbe-Chiuna2), one from Portugal (SM7-SM9SM28), and one that includes one cultivar from Spain (Fino de Jete) and two cultivars from Chile (Serena and Hill).

Similarity values among different cherimoya accessions ranged from 0.16 ('Palazzi2 Tardia' and 'Palazzi3 Precoz' with SP111) to 0.98 ('Bays' and 'Pierce'; 'Mariella' and 'White'; SE18 and SE19; SM4 and SM11), with an average of 0.58 . Several dendrograms were possible, and the dendrogram with the highest cophenetic correlation between the cophenetic matrix and the similarity matrix $(0.63)$ was chosen (Fig. 2). Most of the accessions were grouped in a main cluster "B," where some smaller specific groups could be observed according to geographical origin. Some of these groups have nodes with bootstrap support $>50 \%$ (Fig. 2). Thus, subcluster B1 contains mainly accessions from Peru; subcluster B2, from Chile; subcluster B3, from Bolivia; and subcluster B4, from Ecuador. The cultivars selected in Australia or the United States appear to be scattered in most groups. Cluster A includes mainly accessions from the United States and Australia together with cultivars from Mesoamerica. Cluster C includes most of the accessions from Portugal and Spain separated into two subgroups: Subgroup C1 includes four Spanish genotypes ('Fino de Jete', 'Negrito', 'Pinchudo', and 'Pazicas') as well as one genotype from Peru (410-16), two from Chile, undistinguishable from the Spanish cultivar Fino de Jete, one from Mexico ('Bonita Corona'), and two from Australia ('Burtons' and 'Reretai'). Subgroup C2 contains 26 of the 27 accessions from Portugal (some of them clustered with a strong bootstrap support) and three other cultivars from Spain ('Campas', 'Campas Mejorada', and 'Manteca') that form a cluster, together with one genotype from Peru, one from Australia, and one from the United States. Cluster D includes mostly modern genotypes belonging to breeding programs from the United States and Australia together with three cultivars from

Table 4. Locus name, range size of the amplified fragments, number of alleles (A), effective number of alleles (Ne), probability of identity $(\mathrm{PI})$, observed $(\mathrm{Ho})$ and expected $(\mathrm{He})$ heterozygosities, Wright's fixation index $(F)$, and probability test for departure from Hardy-Weinberg equilibrium (HWE) calculated for 16 SSRs markers in 279 cherimoya cultivars.

\begin{tabular}{|c|c|c|c|c|c|c|c|c|}
\hline SSRs & Size (bp) & A & $\mathrm{Ne}$ & PI & Ho & $\mathrm{He}$ & $\mathrm{F}$ & $\begin{array}{l}\text { Departure } \\
\text { from HWE }\end{array}$ \\
\hline$\overline{\mathrm{LMCH} 1}$ & $291-314$ & 7 & 2.95 & 0.26 & 0.55 & 0.66 & 0.16 & $* *$ \\
\hline LMCH2 & $166-170$ & 3 & 1.49 & 0.53 & 0.10 & 0.32 & 0.68 & $* *$ \\
\hline LMCH4 & $112-128$ & 6 & 3.78 & 0.18 & 0.64 & 0.73 & 0.12 & $* *$ \\
\hline LMCH5 & $157-161$ & 3 & 2.63 & 0.35 & 0.56 & 0.62 & 0.08 & 0.034 \\
\hline LMCH6 & $216-254$ & 10 & 3.90 & 0.17 & 0.57 & 0.74 & 0.22 & $* *$ \\
\hline LMCH8 & $247-251$ & 3 & 1.82 & 0.57 & 0.43 & 0.45 & 0.03 & 0.442 \\
\hline LMCH9 & $170-172$ & 2 & 1.30 & 0.66 & 0.18 & 0.23 & 0.19 & $* *$ \\
\hline LMCH10 & $220-264$ & 4 & 1.84 & 0.45 & 0.39 & 0.46 & 0.13 & $* *$ \\
\hline LMCH11 & $172-175$ & 3 & 2.57 & 0.35 & 0.52 & 0.61 & 0.14 & $* *$ \\
\hline LMCH13 & $305-335$ & 4 & 2.02 & 0.55 & 0.42 & 0.50 & 0.16 & $* *$ \\
\hline LMCH16 & $216-230$ & 6 & 4.39 & 0.15 & 0.64 & 0.77 & 0.16 & $* *$ \\
\hline
\end{tabular}

${ }^{* * *}$ Significant at $P \leq 0.01$. 


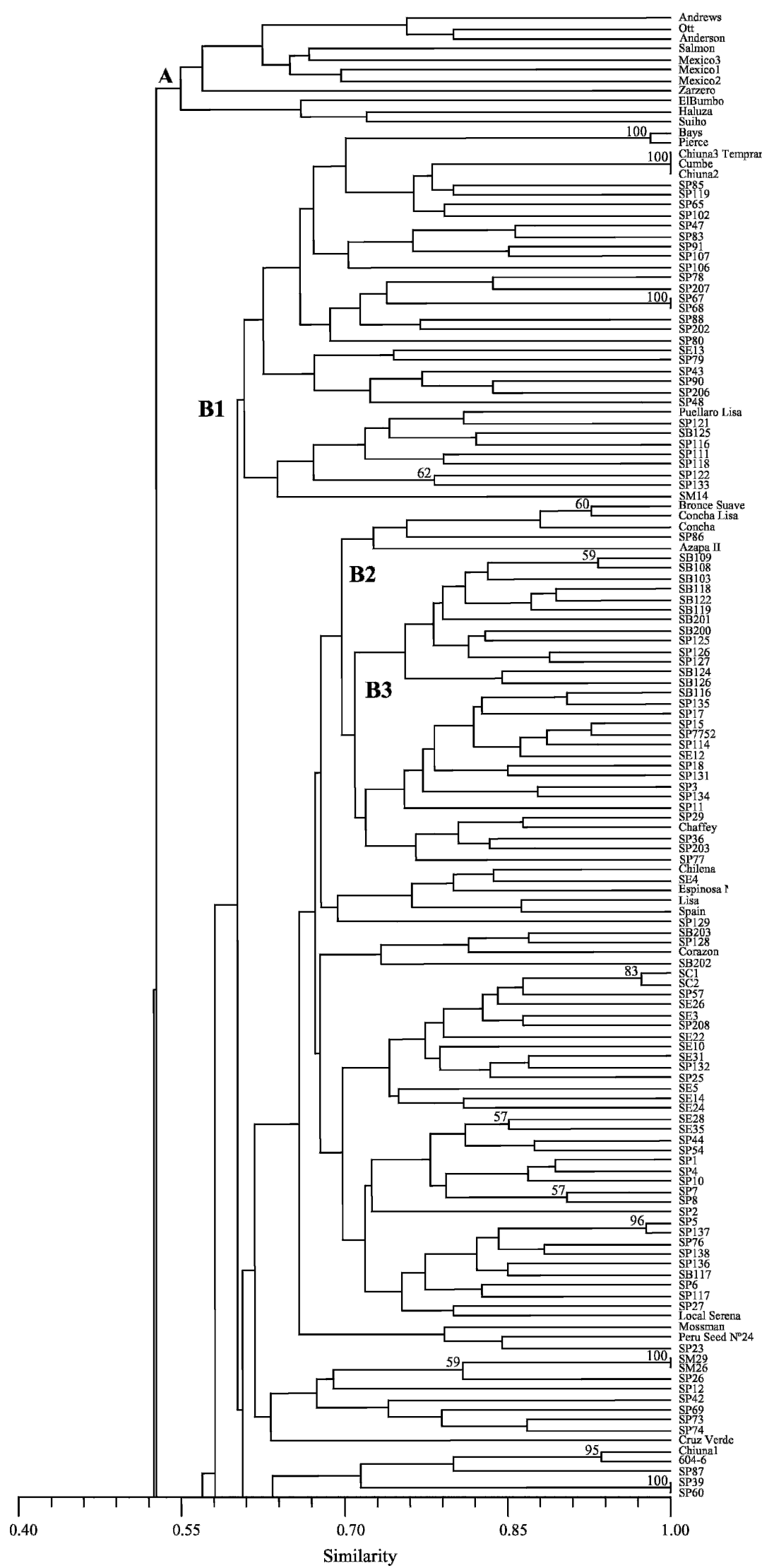

Fig. 2. Dendrogram of the 279 cherimoya accessions studied based on UPGMA analysis using the similarity matrix generated by the Nei and Li coefficient with 16 microsatellite loci. Bootstrap values out of 2000 replicates are shown if 50\% or higher: (A) upper part of UPGMA dendrogram; (B) lower part of UPGMA dendrogram. the United States but apparently obtained in Bolivia (Bolivia Seedling 1, Bolivia Seedling 2, and Bolivia Seedling 3) that cluster with strong bootstrap support $(67 \%)$. Cluster E includes only the three Italian accessions with high bootstrap support (98\%).

Distribution OF GENETIC DIVERSITY. AMOVA calculations were performed with 114 Peruvian and 34 Ecuadorian accessions comparing regions/provinces (Table 5) and valleys among regions/provinces (Table 6). The result of the first analysis showed that, although the great majority of the variation (91.94\%) estimated with SSR markers occurred within regions, a smaller, although significant, proportion $(8.06 \%)$ could be attributed to differences among regions. Genetic differentiation among regions/provinces was significant $\left(F_{S T}=0.081\right)$. On the other hand, the AMOVA among valleys within regions/provinces (Table 6) showed that, although most of the variation occurs within valleys (91.27\%), a small but significant, proportion was attributable to differences among regions $(7.26 \%)$ and among valleys within regions $(1.47 \%), F$ values at different levels $\left(F_{C T}=0.073, F_{S C}=0.016\right.$, and $F_{S T}=0.087$ ) were significant.

With only a few exceptions (one pair of valleys in Lima and one pair in Pichincha), pairwise comparisons of $F_{S T}$ values between valleys from the same regions showed no significant values, whereas consistent significant values were obtained between valleys sampled within different regions (data not shown). Moreover, the number of samples in some valleys was very low. Therefore, we decided to carry out pairwise comparisons of $F_{S T}$ values between regions/provinces (Table 7). All pairwise $F_{S T}$ values were statistically significant, except for Ancash-Piura and Ancash-Lima (Table 7). Results of $F_{S T}$ values between regions were represented after UPGMA analysis in Fig. 3, with a cophenetic value of 0.8 .

\section{Discussion}

In this work, we analyzed with SSRs a worldwide cherimoya collection that contains accessions collected directly from the field in the putative area of origin of cherimoya (Peru and Ecuador) together with accessions obtained through exchange with germplasm collections in different countries. Only the accessions from Peru and Ecuador are expected to directly represent local diversity because wild cherimoya stands are still present in those two countries. The rest of the accessions may have been derived directly from introduction from the area of origin but also by further crosses or selection. However, 
Table 5. Analysis of molecular variance (AMOVA) partitioning genetic variability within and among different regions/provinces from Peru and Ecuador after amplification of 160 cherimoya genotypes with 16 SSRs. $^{z}$

\begin{tabular}{lrccrr}
\hline Source of variation & df & Sum of squares & Variance components & Proportion of variation (\%) & $F$ \\
\hline Among regions/provinces & 5 & 86.757 & 0.325 & 8.06 & 0.081 \\
Within regions/provinces & 286 & 1060.507 & 3.708 & 91.94 & 0.001 \\
Total & 291 & 1147.264 & 4.033 & $<0.001$ \\
\hline
\end{tabular}

${ }^{\mathrm{z}}$ Probabilities were derived from 10,100 permutation tests and represent the probability of observing larger variance components at random.

Table 6. Analysis of molecular variance (AMOVA) partitioning genetic variability within and among different valleys and among six regions/ provinces (Cajamarca, Piura, Lima, Ancash, and Huanuco in Peru; Pichincha in Ecuador) after amplification of 160 cherimoya genotypes with 16 SSRs. $^{\text {z }}$

\begin{tabular}{lrccrr}
\hline Source of variation & df & Sum of squares & Variance components & Proportion of variation (\%) & $F$ \\
\hline Among regions/provinces & 5 & 87.213 & 0.292 & 7.26 & \\
Among valleys & & & & 0.073 & $<0.001$ \\
$\quad$ within regions/provinces & 7 & 33.787 & 0.059 & 1.47 & 0.016 \\
Within valleys & 281 & 1031.418 & 3.670 & 91.27 & 0.050 \\
Total & 293 & 1152.418 & 4.022 & $<0.001$
\end{tabular}

$\overline{{ }^{z} \text { Probabilities were derived from } 10,100 \text { permutations tests and represent the probability of observing larger variance components at random. }}$

information on the origin and on the pedigree of most of these cultivars is scarce.

An average of 4.9 bands/SSR, for 16 SSRs studied, was obtained in 279 cherimoya accessions. These values demonstrate the effectiveness of SSRs to unravel diversity; in a previous study, with 206 accessions and 23 isozyme loci, Perfectti and Pascual (1998) reported an average of 3 alleles/ locus. Only one fixed allele was found, with LMCH16, and a high percentage $(32 \%)$ of rare alleles was observed, mainly occurring in accessions from Australia and the United States. The exact origin of the accessions from these two countries is unknown, but most of them could have a common origin from genotypes not represented in our collection. A similar situation is observed with the accessions from Portugal (Madeira), 10 of which share an exclusive allele.

The average values of the observed (0.44) and expected $(0.53)$ heterozygosities as well as PI $(0.39)$ over the 16 loci studied were similar to those reported previously by Escribano et al. (2004) analyzing 23 genotypes with 13 out of the 16 SSRs employed in this study $(0.43,0.49$, and 0.46 , respectively); consequently, those 23 genotypes seem to be a good representation of the total collection to control general SSR diversity.

Observed heterozygosity was lower than expected for all the loci; therefore, $F$ values were positive, showing heterozygote deficits, and 14 loci (87\%) showed significant departures from Hardy-Weinberg expectations. Different non-exclusive reasons could explain this result, such as nonrandom mating, inbreeding, or presence of subpopulations in the sample. It should be also emphasized that the genotypes studied do not represent a random sample because some of the genotypes were derived from breeding programs and because the germplasm collected directly in the field was selected due to interesting agronomic characteristics in the fruit, such as low number of seeds or skin type.

A reverse relationship was observed between heterozygosity/Ne and PI value; this implies that the higher the heterozygosity detected by a SSR locus, the more useful it is for fingerprint analysis. Thus, $\mathrm{LMCH} 29$ is the most informative locus ( $\mathrm{He}=0.78$ and $\mathrm{PI}=0.15$ ), although $50 \%$ of the microsatellites were highly informative with $\mathrm{He} \geq 0.5$ and $\mathrm{PI} \leq 0.35$.
Just 6 selected loci with the highest $\mathrm{He}$ and the lowest PI (LMCH1, LMCH3, LMCH4, LMCH6, LMCH16, and LMCH29) were sufficient to unambiguously identify all of the 279 accessions analyzed, except those very similar genotypes that could only be differentiated by one allele with other SSRs: LMCH5 ('Campas' and 'Campas Mejorada'), LMCH8 (SM24 and SM1), LMCH9 (SE18 and SE19), LMCH11 ('Mariella' and 'White'), LMCH13 (SC1 and SC2), and LMCH33 ('Balwin' and 'Deliciosa'; SP5 and SP137). Isozymes have been used previously to characterize some of the accessions included in this study (Perfectti and Pascual, 1998); however, the higher resolution power of SSRs allows to distinguish some genotypes that were undistinguishable with isozymes such as 'Campas' and 'Campas Mejorada'; 'Concha', 'Concha Lisa', and 'Azapa II'; SM5 and SM23; SP4 and SE39, SP75, and SE37; and SE10 and 'Chilena'. These results further corroborate the importance of SSRs to optimize management of germplasm collections.

Nine groups of accessions remained undistinguishable: four from Peru, one from Ecuador, three from Madeira (Portugal), and one group that included accessions from Spain and Chile. Regarding the accessions from the cherimoya area of origin, three groups from Peru contained two synonymous genotypes (SP20 from Yungui in Lima and SP201 from Cajamarca; SP39 and SP60, both from Cajamarca; and SP67 and SP68, both from Cajamarca), one contained three genotypes ('Chiuna2', 'Chiuna3 Temprana', and 'Cumbe'), and an additional group from Ecuador contained two genotypes (SE6 and SE16), both collected in Pichincha province. Some of those synonymies, such as SP20-SP201 and SE6-SE16, could be explained by mislabeling mistakes due to code similarity. In other cases, they could be real synonymies because they are local cultivars collected from the same or very close sites, such as SP39-SP60 and SP67-SP68, or selected cultivars with the same origin like 'Chiuna2', 'Chiuna3 Temprana', and 'Cumbe'. When groups from other regions are considered, two groups from Madeira contain two genotypes (SM6-SM22 and SM29-SM26), another group from Madeira contains three genotypes (SM7, SM9, and SM28), and one group contains the most important Spanish cultivar, Fino de Jete, and two Chilean 
Table 7. Population differentiation based on pairwise genetic distances $\left(F_{S T}\right)$ and level of significance among regions (Peru) and provinces (Ecuador) after amplification of 160 cherimoya genotypes with 16 SSRs.

\begin{tabular}{lccccc}
\hline & Cajamarca & Piura & Lima & Ancash & Huanuco \\
\hline Piura & $0.051^{*}$ & & & & \\
Lima & $0.092^{* * *}$ & $0.13^{* *}$ & & & \\
Ancash & $0.051^{* *}$ & $0.069^{\mathrm{Ns}}$ & $0.008^{\mathrm{Ns}}$ & & \\
Huanuco & $0.088^{* * *}$ & $0.14^{* * *}$ & $0.044^{* *}$ & $0.079^{* *}$ & \\
Pichincha & $0.065^{* * *}$ & $0.11^{* *}$ & $0.099^{* * *}$ & $0.084^{* * *}$ & $0.12^{* * *}$ \\
\hline Ns,*,**,***Nonsignificant & or significant at $P<0.05,0.01,0.001$, \\
respectively.
\end{tabular}

cultivars, Hill and Serena. In the case of the cultivars from Madeira, these synonymies could be explained by clonal propagation of locally selected cultivars. However, in the last case, 'Hill' and 'Serena' could have been developed from 'Fino de Jete' buds taken to Chile. In all cases, we cannot discard mislabeling or other mistakes during germplasm exchange. Analyses of the same cultivars maintained in different collections will allow elucidation of the mislabeling hypotheses.

Genetic relationships among the accessions studied have been investigated using UPGMA cluster analysis. A low (0.63) cophenetic correlation between the cophenetic and the similarity matrixes was obtained, suggesting that some accessions can switch among groups probably due to the mixture in the analyzed accessions of local genotypes that originated in the area of origin of cherimoya and cultivars derived from crosses and selection in other areas as well as the possible germplasm movement among different regions. This is reflected in the absence of strong bootstrap support for most of the main nodes of the dendrogram. Moreover, there is a lack of information about the exact origin of the most modern cultivars. We can observe four main clusters in the dendrogram and some smaller clusters that are composed mainly by accessions from the same geographic origin, some of them with strong bootstrap support. The cultivars selected in Australia or the United States appear scattered in most groups, indicating their development from germplasm collected in different areas although some of them cluster separately in clusters A and D. Thus, cluster A includes mainly accessions from the United States and Australia together with cultivars from Mesoamerica. Popenoe (1974) indicated the introduction in the United States of genotypes from Mexico, and this genetic material could be the basis for crosses made in other countries, such as Australia, resulting in the development of some of the genotypes studied. Unfortunately, the number of accessions from Mesoamerica in our collection is low. Cluster D includes mostly modern genotypes belonging to breeding programs from the United States and Australia together with three cultivars putatively from Bolivia (Bolivia Seedling 1, Bolivia Seedling 2, and Bolivia Seedling 3) that were introduced into our collection from the United States. Those three genotypes show a high similarity value among them $(0.84)$, and they cluster with a high bootstrap support $(67 \%)$, suggesting that they could be siblings from the same cross or derived from the same place or tree. Accessions from almost all of the origins, including the accessions from the putative area of origin of cherimoya, are grouped in cluster B with several subclusters according to geographical origin: B1 contains mainly accessions from Peru, B2 from Chile, B3 from
Bolivia, and B4 from Ecuador. Cluster $\mathrm{C}$ includes most the accessions from Portugal and Spain separated into two subgroups and several accessions from other origins. Subgroup C1 includes four the Spanish genotypes as well as one genotype from Peru, two from Chile, and one from Mexico, while subgroup C2 contains only genotypes from Portugal (27) and three cultivars from Spain, together with one genotype from Peru. Movement of genotypes by exchange among the different countries could explain this grouping. In fact, genotypes from Spain, Portugal, and Italy share most of the same alleles in different combinations except one allele exclusive of 'Fino de Jete' and another present in 10 cultivars from Portugal. This could be in line with a common origin of most of the European genotypes from Spain (Guirado et al., 2003). Finally, Cluster E includes only the three Italian genotypes, forming a highly homogeneous group with a high level of homozygosity (9 to 16 SSRs studied, data no shown) and bootstrap support (98\%), pointing toward a common origin from a small number of seeds or buds.

In vegetatively propagated fruit tree species, the domestication process has involved few recombination cycles; consequently, domesticated genotypes are only a few generations removed from their wild ancestors. This is especially the case in underused species, such as cherimoya, for which the process of domestication is incipient; consequently, cultivated genotypes could still reflect the genetic variation present in wild populations. Thus, to study the geographic distribution of genetic diversity in the putative cherimoya area of origin, we performed AMOVA analyses with only accessions that originated from direct field collections in Peru and Ecuador. Because current geopolitical frontiers do not represent the actual distribution of genetic diversity, analyses were carried out without considering the country of origin. The results showed low $F$ values, but the $P$ values obtained (Tables 5 and 6) indicated significant differences among valleys and regions/provinces. The lowest differentiation $(F=0.01585$; $P=0.0244$ ) occurs among valleys within the same region. Larger differences were observed among regions: Cajamarca, Piura, Lima, Ancash, and Huanuco from Peru and Pichincha province in northern Ecuador $(F=0.0726, P=0.0001)$ and valleys from different regions $(F=0.0873, P=0.00000)$. Pairwise $F_{S T}$ between regions/provinces were significant in all of the comparisons except between Ancash and Lima (both in central Peru) and Ancash and Piura (in northern Peru). As a consequence, the UPGMA dendrogram based on pairwise $F_{S T}$ distances between different regions/provinces differentiates two main groups in Peru - the northern (Cajamarca and Piura) and the central (Lima, Ancash, Huanuco) regionswhereas the only province studied in Ecuador (Pichincha, in the north of the country) seems to be closer to northern than to central Peruvian regions. However, it should be noted that Piura with four accessions and Ancash with six are represented by a low number of individuals; consequently, inferences from those two regions should be taken cautiously.

Ninety percent of the variability detected in this germplasm collection occurred within valleys or regions and only $\approx 10 \%$ among valleys or regions. If we accept the hypothesis of local domestication by farmers from wild trees, then this structure where most of the variability is detected within valleys could probably be due to gene flow within and among populations in different valleys because of the allogamous nature of cherimoya, i.e., protogynous dichogamy, which promotes cross 

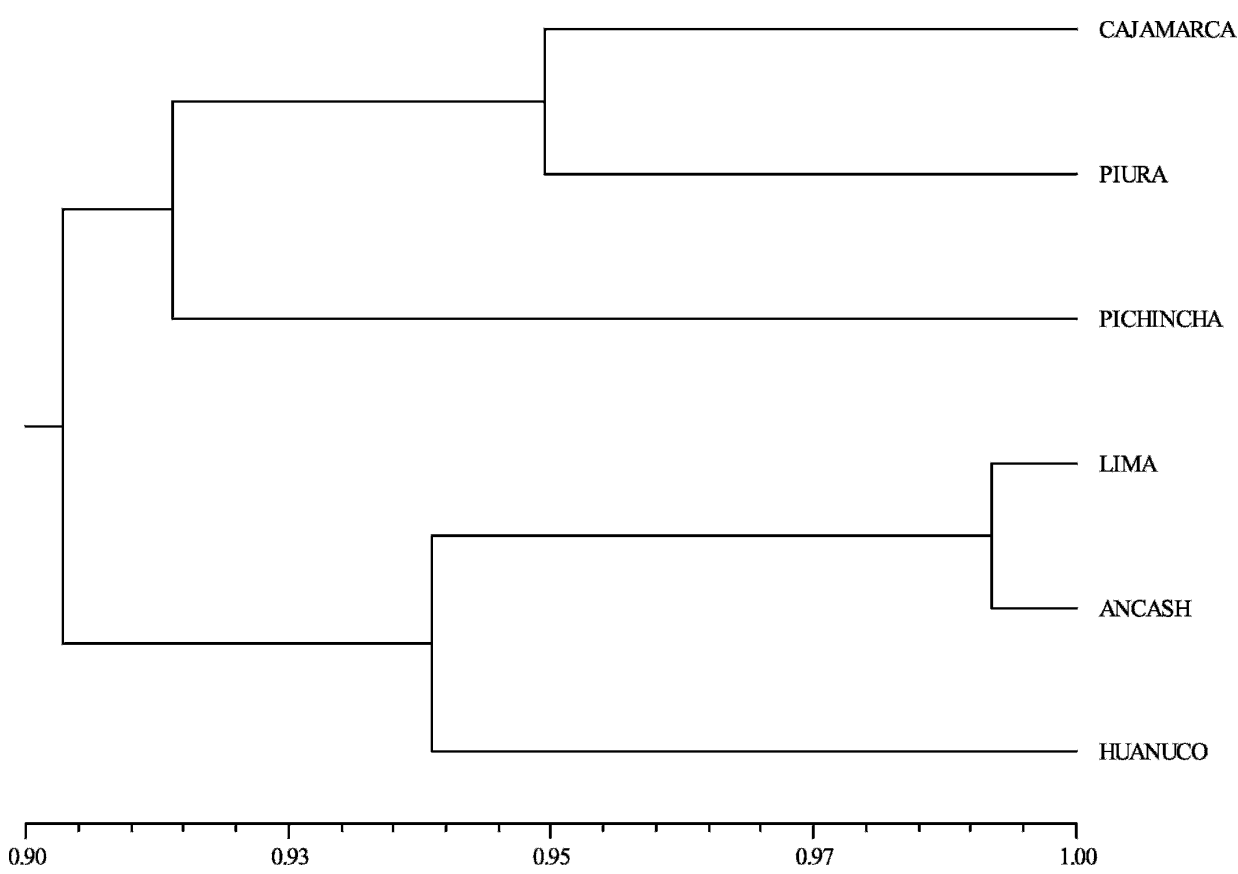

Fig. 3. UPGMA dendrogram of population pairwise genetic distances $\left(F_{S T}\right)$ among regions/provinces in Ecuador and Peru derived from AMOVA calculations after amplification of 160 cherimoya genotypes with 16 SSRs.

ulations and of total genetic diversity. In any case, results obtained in this work show a much higher diversity within than among populations, and this could have an effect on future cherimoya germplasm collections and on in situ genetic resource conservation in the area of origin. Sampling of a higher number of individuals within populations should probably be favored against a low number of individuals within a high number of different populations. Additional studies on the distribution of genetic diversity with wild, semi-cultivated, and cultivated individuals from the putative areas of origin and from Mesoamerica of cherimoya collected at random will allow us to measure the diversity bias in our collection, to discern the conflicting hypothesis on cherimoya origin and diversification, and to estimate the diversity changes during the domestication process. An unbiased estimation of the germplasm diversity distribution in cher-

pollination. Consequently, out-crossing could allow significant gene flow among populations in different valleys, reducing the variability among them. This partition of genetic variation with high levels of interpopulation gene flow is common to other out-crossing plant species (Bartish et al., 1999; Bussell, 1999, and references therein; Hamrick and Godt, 1996; Mattner et al., 2002; Reis and Grattapaglia, 2004) and is further stressed in woody, long-lived plant species that tend to show low genetic differentiation among populations (Bartish et al., 1999; Hamrick and Godt, 1996). In the case of cherimoya, gene flow among populations could be also favored by animal dispersal, which could transport seeds among populations, as has been reported for several Annona species (Flores, 2002). Moreover, A. cherimola can be considered in some areas to be a semidomesticated species; consequently, fruit could also have been transported by farmers and traders among valleys and regions from pre-Columbian times. Cherimoya seeds germinate easily, and this would favor gene flow among different populations after fruit movement. On the other hand, the presence of high mountain ranges in the putative cherimoya area of origin separating the valleys where cherimoya can grow together with regression of species distribution due to human activities could act against this gene flow among populations, inducing an isolation process still too short to be reflected in different structuring of the variability among populations. Further analyses including the few remaining wild cherimoya stands will be needed to address this point.

Results from this study indicate that SSRs are excellent codominant markers to improve cherimoya germplasm management, allowing researchers to distinguish synonymies and homonymies and to study cherimoya conserved diversity. The fact that the accessions collected in the putative center of origin of this species do not represent a totally random sample because they were collected on the basis of some phenotypic traits may have resulted in underestimation of differences among pop- imoya populations in the areas of origin of the species will allow us to develop appropriate sampling strategies in order to optimize ex situ conservation of cherimoya genetic resources and to define strategies for in situ and on-farm conservation.

\section{Literature Cited}

Andrés-Agustín, J., F. González-Andrés, R. Nieto-Ángel, and A.F. Barrientos-Priego. 2006. Morphometry of the organs of cherimoya (Annona cherimola Mill.) and analysis of fruit parameters for the characterization of cultivars, and Mexican germplasm selections. Scientia Hort. 107:337-346.

Bartish, I.V., N. Jeppson, and H. Nybom. 1999. Population genetic structure in the dioecious pioneer plant species Hippophae rhamnoides investigated by random amplified polymorphic DNA (RAPD) markers. Mol. Ecol. 8:791-802.

Bonavia, D., C.M. Ochoa, O. Tovar, and R.C. Palomino. 2004. Archaeological evidence of cherimoya (Annona cherimola Mill.) and guanabana (Annona muricata L.) in ancient Peru. Econ. Bot. 58:509-522.

Bussell, J.D. 1999. The distribution of random amplified polymorphic DNA (RAPD) diversity amongst populations of Isotoma petraea (Lobeliaceae). Mol. Ecol. 8:775-789.

Chatrou, L.W., H. Rainer, and P.J.M. Maas. 2004. Annonaceae, p. 18 20In: N. Smith, S.A. Mori, A. Henderson, D.W. Stevenson, and S.V. Heald (eds.). Flowering plants of the neotropics. Princeton University Press, Princeton, N.J.

Ellstrand, N.C. and J.M. Lee. 1987. Cultivar identification of cherimoya (Annona cherimola Mill) using isozyme markers. Scientia Hort. 32:25-31.

Escribano, P., M.A. Viruel, and J.I. Hormaza. 2004. Characterization and cross-species amplification of microsatellite markers in cherimoya (Annona cherimola Mill., Annonaceae). Mol. Ecol. Notes 4:746-748.

Esquinas-Alcazar, J. 2005. Protecting crop genetic diversity for food security: political, ethical and technical challenges. Nat. Rev. Genet. 6:946-953. 
Excoffier, L., G. Laval, and S. Schneider. 2005. ARLEQUIN, ver. 3.0: an integrated software package for population genetics data analysis. Evolutionary Bioinformatics Online 1:47-50.

Excoffier, L., P. Smouse, and J. Quattro. 1992. Analysis of molecular variance inferred from metric distances among DNA haplotypes: application to human mitochondrial DNA restriction data. Genetics 131:479-491.

Flores, E.M. 2002. Seed biology, p. 1-106. In: J. Vozzo (ed.). Tropical tree seed manual. U.S. Dept. Agr., For. Serv., Agr. Hdbk. 721.

Guirado, E., J.M. Hermoso, M.A. Pérez de Oteyza, and J.M. Farré. 2003. Introducción al cultivo del chirimoyo. Caja Rural de Granada, Granada, Spain.

Gupta, P.K. and R.K. Varshney. 2000. The development and use of microsatellite markers for genetic analysis and plant breeding with emphasis on bread wheat. Euphytica 113:163-185.

Hamrick, J.L. and J.W. Godt. 1996. Effects of life history traits on genetic diversity in plant species. Philos. Trans. Royal Soc. London B 351:1291-1298.

Mattner, J., G. Zawko, M. Rossetto, S.L. Krauss, K.W. Dixon, and K. Sivasithamparam. 2002. Conservation genetics and implications for restoration of Hemigenia exilis (Lamiaceae), a serpentine endemic from Western Australia. Biol. Conserv. 107:37-45.

Nei, M. 1973. Analysis of gene diversity in subdivided populations. Proc. Natl. Acad. Sci. U.S.A. 70:3321-3323.

Nei, M. and W.H. Li. 1979. Mathematical model for studying geneticvariation in terms of restriction endonucleases. Proc. Natl. Acad. Sci. U.S.A. 76:5269-5273.

Paetkau, D., W. Calvert, I. Stirling, and C. Strobeck. 1995. Microsatellite analysis of population-structure in Canadian polar bears. Mol. Ecol. 4:347-354.

Pascual, L., F. Perfectti, M. Gutierrez, and A.M. Vargas. 1993. Characterizing isozymes of Spanish cherimoya cultivars. HortScience 28:845-847.

Perfectti, F. and L. Pascual. 1998. Characterization of cherimoya germplasm by isozyme markers. Fruit Var. J. 52:53-62.

Pérez de Oteyza, M.A., J.M. Farré-Massip, J.M. Hermoso-González, and A. Ruiz-Nieto. 1999. El banco español de germoplasma de chirimoyo. Parámetros estudiados y su variabilidad. Actas Hort. 25:7-12.

Popenoe, W. 1921. The native home of the cherimoya. J. Hered. 12:331-337.
Popenoe, W. 1974. The annonaceous fruits, p. 161-195. In: W. Popenoe (ed.). Manual of tropical and subtropical fruits. The annonaceous fruits (facsimile of the 1920 edition). Hafner Press, New York

Popenoe, H., S.R. King, J. Leon, L.S. Kalinowski, N.D. Vietmeyer, and M. Dafforn. 1989. Lost crops of the Incas. Little-known plant of the Andes with promise for worldwide cultivation. National Academy Press, Washington, D.C.

Pozorski, T. and S. Pozorski. 1997. Cherimoya and guanabana in the archaeological record of Peru. J. Ethnobiol. 17:235-248.

Rahman, M., T. Shimada, T. Yamamoto, J.Y. Yonemoto, and M. Yoshida. 1998. Genetical diversity of cherimoya cultivars revealed by amplified fragment length polymorphism (AFLP) analysis. Breed. Sci. 48:5-10.

Reis, A.M.M. and D. Grattapaglia. 2004. RAPD variation in a germplasm collection of Myracrodruon urundeuva (Anacardiaceae), an endangered tropical tree: Recommendations for conservation. Genet. Resources Crop Evol. 51:529-538.

Ronning, C.M., R.J. Schnell, and S. Gazit. 1995. Using randomly amplified polymorphic DNA (RAPD) markers to identify Annona cultivars. J. Amer. Soc. Hort. Sci. 120:726-729.

Schroeder, C.A. 1971. Pollination of cherimoya. Calif. Avocado Soc. Yrbk. 44:119-122.

Tanksley, S.D. and S.R. McCouch. 1997. Seed banks and molecular maps: unlocking genetic potential from the wild. Science 277:10631066.

Van Damme, P., V. Van Damme, and X. Scheldeman. 2000. Ecology and cropping of cherimoya (Annona cherimola Mill) in Latin America. New data from Ecuador. Fruits 55:195-206.

Van de Peer, Y. and R. de Wachter. 1994. TREECON for Windows: a software package for the construction and drawing of evolutionary trees for the Microsoft Windows environment. Comput. Appl. Biosci. 10:569-570.

Viruel, M.A. and J.I. Hormaza. 2004. Development, characterization and variability analysis of microsatellite in lychee (Litchi chinensis Sonn, Sapindaceae). Theor. Appl. Genet. 108:896-902.

Wright, S. 1951. The genetical structure of populations. Ann. Eugen. 15:323-354.

Yeh, F.C. and T.B.J. Boyle. 1997. Population genetic analysis of co-dominant markers and quantitative traits. Belg. J. Bot. 129:157. 